\title{
LEGISLAÇÃO AMBIENTAL BRASILEIRA E GEOCONSERVAÇÃO: ANÁLISE COMPARATIVA DO ENQUADRAMENTO LEGAL NO BRASIL, PORTUGAL E ESPANHA
}

\author{
Magda Wolemberg da Silva FERREIRA \\ José Bernardo Rodrigues BRILHA \\ Adriana Ponce Coelho CERÂNTOLA
}

\begin{abstract}
RESUMO
A geoconservação tem por finalidade a proteção e gestão do patrimônio geológico e dos elementos de geodiversidade com valor excepcional. A classificação é uma das ações que formam uma estratégia de geoconservação que visa a proteção legal desse patrimônio. Por se tratar de uma temática recente, são poucos os países que apresentam dispositivos legais destinados à proteção específica do patrimônio geológico. No contexto europeu, a geoconservação ganhou relevância no ordenamento jurídico de alguns países, como o Reino Unido, Espanha e Portugal. Já no Brasil, apesar das leis ambientais em sua maioria estarem voltadas para a proteção da biodiversidade, há avanços significativos relativos à proteção legal de alguns tipos de patrimônio geológico. O presente trabalho tem por objetivo analisar o enquadramento legal brasileiro que suporta a geoconservação, fazendo uma comparação com os modelos legislativos de Portugal e Espanha. Assim, embora não exista uma lei específica para o patrimônio geológico, os resultados obtidos ao longo do estudo demonstram que, no ordenamento jurídico brasileiro, o patrimônio espeleológico e paleontológico estão bem classificados com planos e ações de conservação em andamento. Espera-se que a presente análise contribua para o conhecimento da necessidade de implementação de uma estratégia de geoconservação adaptada à realidade brasileira, em prol da proteção do patrimônio geológico no Brasil.
\end{abstract}

Palavras-chave: Geoconservação; Patrimônio geológico; Geodiversidade; Legislação ambiental.

\section{ABSTRACT}

BRAZILIAN ENVIRONMENTAL LEGISLATION AND GEOCONSERVATION: COMPARATIVEANALYSIS OF THE LEGALFRAMEWORK IN BRAZIL, PORTUGAL AND SPAIN. The aim of geoconservation is the protection and management of geological heritage and other geodiversity elements of exceptional value. Statutory protection is one action that constitutes a geoconservation strategy, but there are still few countries having the legal means for adequate protection of geological heritage. In the European context, geoconservation has gained relevance in the legal system of such countries as the United Kingdom, Spain and Portugal. In Brazil, although environmental laws are mostly focused on the protection of biodiversity, there have been significant advances regarding the legal protection of some types of geological heritage. This paper analyzes the Brazilian legal framework that supports geoconservation and compares it to the legislative models of Portugal and Spain. Thus, although there is no specific Brazilian law regarding geological heritage, the results of the study show that in the legal system of Brazil the speleological and paleontological patrimonies are well contemplated within conservation plans and actions currently underway. This analysis is meant to raise awareness regarding the need to implement a geoconservation strategy adapted to Brazil for the protection of its geological heritage.

Keywords: Geoconservation; Geoheritage; Geodiversity; Environmental legislation. 


\section{INTRODUÇÃO}

No século XX, em meio à crise ambiental e à crescente preocupação com o esgotamento dos recursos não renováveis, surgiram as primeiras manifestações conservacionistas em defesa do uso sustentável do meio ambiente e da manutenção da diversidade biológica. Essa percepção da degradação ambiental em nível nacional e mundial deu origem aos novos paradigmas de racionalidade ambiental com movimentos de conscientização ecológica e ações diversas, cujo objetivo era influenciar a legislação e as atitudes de cada Estado e seus respectivos governantes (RONCAGLIO \& JANKE 2009).

Em 1972, a Conferência de Estocolmo reuniu 113 países e apresentou as primeiras questões relacionadas ao modelo de desenvolvimento sustentável, sendo considerada um marco importante para a conservação do meio ambiente (ABAIDE 2009). Nesse contexto, a defesa da biodiversidade ganhou maior destaque nas políticas públicas e ambientais, enquanto a proteção dos elementos abióticos foi esquecida e tratada de modo mais superficial.

Autores como GRAY (2004) e PEREIRA (2010) apontam que, nessa tendência, o termo "geodiversidade" ficou muito aquém do que poderia ser, revelando-se a falta de sensibilidade na sua defesa e conservação. Para BRILHA (2005), a geodiversidade compreende os aspectos não vivos da Terra e não apenas os provenientes do passado, mas também os processos naturais que ocorrem na atualidade e que dão origem a novos testemunhos.

Cabe salientar que a natureza é constituída pela variedade de elementos bióticos e abióticos. Tais elementos estão inter-relacionados de modo que as iniciativas de proteção e conservação devem considerar isso. Contudo, apesar da geodiversidade possuir uma importância equivalente à da biodiversidade, as ações que favorecem a conservação da natureza biótica sempre foram prioritárias em detrimento da conservação dos elementos abióticos. Nessa conjuntura, a geoconservação resulta da necessidade de mudança da visão dos cientistas para a conservação da vertente geológica da natureza. Assim, a geoconservação visa proteger o patrimônio geológico e os elementos de geodiversidade de valor excepcional frente às ameaças a que estão sujeitos, além de promover o uso sustentável desses elementos.

CARCAVILLA (2012) considera que uma estratégia de geoconservação deve promover as seguintes ações e na seguinte ordem: i) inventário, ii) legislação, iii) geoconservação e iv) divulgação. Estas ações estão relacionadas e interligadas, servindo de base para o desafio de explorar, conservar, preservar e usufruir.

No que tange à legislação, por ser uma temática recente, são poucos os países que dispõem de dispositivos legais destinados à proteção do patrimônio geológico. O Reino Unido é um dos países de referência a este respeito, tendo publicado leis para a proteção de sítios geológicos desde a década de 1940. Espanha e Portugal são dois exemplos de países que integraram mais recentemente a legislação nesse contexto. Quanto ao Brasil, é habitual a consideração de que não existe uma legislação específica para proteger diretamente o patrimônio geológico. Contudo, há mecanismos legais que servem de suporte para a proteção indireta dos elementos em tela, além de existirem avanços significativos nas leis de proteção do patrimônio espeleológico e paleontológico.

Nesse sentido, o presente trabalho apresenta uma análise do enquadramento legal da geoconservação na legislação ambiental do Brasil. Para tanto, foram identificados alguns dos princípios comuns que norteiam os mecanismos legais existentes tanto em Portugal quanto na Espanha. Também foram levantados alguns dos dispositivos legais aplicáveis na formulação da legislação em defesa do patrimônio geológico brasileiro.

Para a consecução dos objetivos propostos no presente trabalho, foi realizado um levantamento bibliográfico nas áreas do meio ambiente, patrimônio geológico e geoconservação. Em seguida, graças à extensa pesquisa documental, foram analisadas as normativas relacionadas ao meio ambiente, documentações técnicas e legislação de conservação e proteção ambiental. Por fim, os dados coletados foram integrados, organizados e discutidos.

\section{LEGISLAÇÃO AMBIENTAL E GEOCONSERVAÇÃO NO BRASIL}

O Brasil, com uma área de cerca de 8,5 milhões de $\mathrm{km}^{2}$, é conhecido como um dos países com a maior extensão territorial do mundo (IBGE 2015). O país possui enorme riqueza de recursos naturais, não apenas em biodiversidade, mas também em geodiversidade. No âmbito da legislação ambiental brasileira, existe um histórico importante que data do período colonial até os dias atuais.

A preocupação do Brasil com a conservação da natureza se expressa a partir de 1605 com a ins- 
tituição do Regimento do Pau-Brasil e do Decreto $\mathrm{n}^{\mathrm{o}} 8.843$, de 26 de junho de 1911, que instituiu a Reserva Florestal no Território do Acre.

O pesquisador WAINER (1999) considerou como as primeiras iniciativas legais relativas à questão ambiental no Brasil: o Código Florestal, promulgado em 1934; a criação do Parque Nacional de Itatiaia, em 1937; e o Decreto-Lei no 25/1937 (proteção do patrimônio histórico e artístico nacional).

Segundo LITTLE (2003), apesar das fortes políticas de desenvolvimento industrial no período marcado pelo "milagre econômico", o Brasil deu passos importantes na mudança de paradigma ao buscar a conscientização para o uso dos recursos ambientais e a diminuição da degradação. Em 1973, por meio do Decreto $\mathrm{n}^{\circ} 73.030$, de 30 de outubro, foi instituída a Secretaria Especial do Meio Ambiente - SEMA.

Cabe destacar também que o país é signatário de duas convenções internacionais para a proteção do patrimônio natural e cultural, influenciado pelo advento das políticas preservacionistas e sob a inspiração da participação brasileira na Conferência das Nações Unidas para o Meio Ambiente. O Decreto $\mathrm{n}^{\circ} 80.978$, de 12 de dezembro de 1977, que promulgou a Convenção UNESCO/1972, em conjunto com o Decreto Legislativo ${ }^{0} 74 / 1977$, possui grande relevância para a proteção do patrimônio cultural e natural pois está fundamentado na participação do Brasil na Conferência das Nações Unidas em Estocolmo/1972, bem como à sua adesão à Convenção para a Proteção do Patrimônio Mundial, Cultural e Natural. A convenção é um importante instrumento de proteção desses patrimônios frente às ameaças de degradação e destruição, com o intuito de conservá-los para as gerações futuras. Estabelece em seus dispositivos, respeitando-se a soberania dos países signatários, a definição dos patrimônios, criação de comitês, fundos e as competências dos participantes relativamente à identificação, proteção e conservação (BRASIL 1977).

O Decreto $\mathrm{n}^{\circ} 5.753$, de 12 de abril de 2006, por sua vez, promulga a Convenção para a Salvaguarda do Patrimônio Cultural Imaterial da UNESCO, adotada em Paris (17 de outubro de 2003).

O Brasil é uma federação de estados dotados de autonomia política e administrativa, o que permite que as leis ambientais possuam âmbitos diferentes (federal, estadual e municipal). Assim, para se analisar o enquadramento da geoconservação na legislação ambiental brasileira, foram estudadas as leis nas diferentes esferas administrativas, identificando-se os dispositivos mais apropriados para a proteção do patrimônio geológico.

\subsection{Leis federais}

No âmbito da esfera federal, foram analisadas a Carta Magna, os decretos, as portarias e as leis relativas à gestão e proteção do meio ambiente, identificando-se as referências aplicáveis ao patrimônio geológico e aos elementos de geodiversidade.

A Constituição da República Federativa do Brasil, de 5 de outubro de 1988, revela a preocupação do país com as questões ambientais ao apresentar um capítulo dedicado ao meio ambiente. Em seu artigo 225, atribui ao poder público e à sociedade o dever de proteger e preservar o meio ambiente em prol das gerações presentes e futuras. Para tanto, dispõe sobre as medidas cabíveis à União, Estados e Municípios visando assegurar a sua integridade (Art. 225, $\S 1^{\circ}$, incisos I ao VII). Estabelece ainda a tríplice responsabilidade em matéria ambiental, em que os agentes de danos ambientais deverão cumprir sanções penais, administrativas e civis concomitantemente.

No que tange à proteção dos elementos abióticos, a Constituição de 1988 apresenta dispositivos que podem ser utilizados na proteção direta e indireta. O artigo 20 (incisos V e X) classifica as cavidades naturais como bens da União e como patrimônio cultural. Como complemento, os artigos 23 e 24 estabelecem à União, Estados e Distrito Federal a competência na gestão e proteção do patrimônio histórico, cultural artístico e das paisagens naturais. Já o inciso V do artigo 216, além de incluir a proteção do patrimônio espeleológico, contempla também o patrimônio paleontológico como bem histórico e cultural (BRASIL 1988).

A Lei ${ }^{\circ} 6.938$, de 31 de agosto de 1981, regulamentada pelo Decreto $n^{\circ} 88.351 / 1983$, é considerada um marco na legislação ambiental brasileira, pois além de criar a Política Nacional do Meio Ambiente, definiu instrumentos, órgãos responsáveis e princípios para a defesa e melhoria da qualidade ambiental no país (BRASIL 1981). Como complemento a essa legislação, foi publicada a Lei $\mathrm{n}^{\mathrm{o}} 9.605$, de 12 de fevereiro de 1998, regulamentada pelo Decreto ${ }^{\circ} 6.514 / 2008$. Conhecida como a Lei dos Crimes Ambientais, ela trouxe a definição das sanções e penalidades às condutas e atividades lesivas ao meio ambiente. 
Em relação ao patrimônio geológico, o estudo realizado permitiu verificar que a preocupação inicial relativa ao patrimônio paleontológico se deu por meio do Decreto-lei $\mathrm{n}^{\circ} 25$, de 30 de novembro de 1937. Ele foi classificado no âmbito histórico-cultural, sendo protegido por meio do ato administrativo do tombamento. Nesse contexto, o Decreto-lei no $4.146 / 1942$, de 4 de março, é considerado o primeiro instrumento legal relativo à proteção direta do patrimônio paleontológico, pois dispõe sobre a proteção dos depósitos fossilíferos, além de atribuir ao Departamento Nacional de Produção Mineral (DNPM) a competência para fiscalizar e gerir a sua extração.

A Lei ${ }^{\circ} 9.985 / 2000$, de 18 de julho, regulamentada pelo Decreto $n^{\circ} 4.340 / 2002$, é um outro dispositivo legal relevante na conservação da natureza no Brasil, ao instituir o Sistema Nacional de Unidades de Conservação (SNUC), que tem por finalidade sistematizar a criação e gestão das áreas protegidas. Essa Lei Federal, embora represente uma legislação de conservação da natureza voltada especialmente para a proteção da biodiversidade, é considerada um avanço na proteção dos elementos abióticos uma vez que apresenta dispositivos específicos para a proteção dos valores geológicos e geomorfológicos. Destaca-se, no artigo $4^{\circ}$, dois objetivos do SNUC: "VI - proteger paisagens naturais e pouco alteradas de notável beleza cênica; VII - proteger as características relevantes de natureza geológica, geomorfológica, espeleológica, arqueológica, paleontológica e cultural" (BRASIL 2000).

Em consonância com a proteção das áreas naturais, a lei supracitada estabelece dois grupos de unidades de conservação e seus respectivos planos de manejos: Unidades de Proteção Integral (uso indireto) e Unidades de Uso Sustentável (uso direto), garantindo um suporte às políticas de proteção ambiental e, consequentemente, às ações de geoconservação, ainda que de forma indireta. Assim, as Unidades de Proteção Integral (modalidade de gestão na qual o uso dos recursos é restrito para a preservação da natureza frente às alterações provocadas pela ação humana) podem assegurar a proteção do patrimônio geológico ao incluírem elementos relevantes de natureza geológica. Dentre as categorias desse grupo de unidade de conservação, destacam-se o Parque Nacional e o Monumento Natural (artigos 11 e 12) como compatíveis à proteção do patrimônio geológico. Em relação às Unidades de Uso Sustentável, destacam-se cinco categorias: Área de Proteção
Ambiental, Área de Relevante Interesse Ecológico, Reserva Extrativista, Reserva de Desenvolvimento Sustentável e Reserva Particular do Patrimônio Natural (artigos 15, 16, 18, 20 e 21 da Lei $n^{\circ}$ 9.985/2000). As Áreas de Proteção Ambiental (APAs) são unidades que abrangem áreas extensas do território nacional e têm por finalidade preservar a diversidade biológica e assegurar a sustentabilidade dos recursos naturais.

Do exposto, cabe inferir que, apesar da legislação ambiental brasileira estar centrada na biodiversidade, a proteção dos elementos abióticos não é excluída e pode ser efetivada de modo indireto. Embora a proteção legal do patrimônio geológico como um todo não esteja prevista especificamente nas leis ambientais, há alguns tipos de patrimônio geológico (espeleológico e paleontológico) que já possuem dispositivos legais específicos.

Contatou-se que, além das leis supracitadas, a proteção do patrimônio paleontológico tem seu amparo na recente Portaria do DNPM n ${ }^{\circ}$ $155 / 2016$, de 12 de maio, que revogou a portaria $n^{0} 542 / 2014$, que versava sobre a extração de fósseis. Essa nova portaria veio como um instrumento para a normatização do aproveitamento e exploração dos recursos minerais, apresentando artigos específicos sobre os procedimentos de autorização e comunicação prévias para a extração de fósseis (nos termos do Decreto-lei no 4.146/1942, de 4 de março).

O patrimônio espeleológico, por sua vez, amparado inicialmente pela Constituição Federal em seus artigos 20, inciso X, e 216, inciso V, teve sua regulamentação por meio do Decreto $\mathrm{n}^{\circ}$ 99.556/1990, de $1^{\circ}$ de outubro, que estabeleceu a proteção das cavidades naturais enquanto patrimônio cultural brasileiro, defendendo o estudo de impacto ambiental e aplicação de penalidades sobre as infrações cometidas segundo a Política Nacional do Meio Ambiente.

A Portaria do IBAMA n ${ }^{\circ} 887 / 1990$, de 15 de junho, somou-se à legislação anterior, ao estabelecer o diagnóstico do patrimônio espeleológico nacional por meio do levantamento e análise das áreas críticas, com a devida definição de ações para a sua proteção e uso. Nessa linha, a Resolução CONAMA n ${ }^{\circ} 347 / 2004$, de 10 de setembro, instituiu o Cadastro Nacional de Informações Espeleológicas - CANIE, a fim de disciplinar o uso do patrimônio espeleológico por meio de mecanismos de controle ambiental. Assim, configurou-se num importante instrumento legal de con- 
servação ao buscar a mitigação da degradação das cavidades naturais.

Já o Decreto ${ }^{0} 6.640 / 2008$, de 7 de novembro, é considerado um divisor de fases que trouxe mudanças significativas para a proteção do patrimônio espeleológico. Ao estabelecer a classificação das cavidades naturais segundo o grau de relevância e sua localização, causou manifestações e discussões entre juristas e cientistas, segundo o posto de vista de que todas as cavidades são relevantes e não poderiam ser destruídas para satisfazerem alguns interesses econômicos (RUCHKYS 2015).

Após discussões e debates sobre a liberalidade do decreto supracitado, o Ministério do Meio Ambiente lançou a Instrução Normativa $n^{\circ}$ $02 / 2009$, de 20 de agosto, estabelecendo as novas diretrizes para a classificação do grau de relevância das cavidades naturais segundo as especificidades (atributos) de cada uma e de acordo com o contexto local ou regional. Os artigos $2^{\circ}$ e $8^{\circ}$ da referida norma estabelecem que as cavidades naturais serão classificadas segundo o grau máximo, alto, médio ou baixo, considerando-se a importância dos atributos com enfoque local (por exemplo: presença de registros paleontológicos e estrutura geológica de interesse científico).

Como complemento, a Portaria do ICMBio $n^{\circ}$ 078/2009, de 3 de setembro, criou o Centro Nacional de Pesquisa e Conservação de Cavernas (CECAV), órgão responsável pela gestão do conhecimento científico aplicado à conservação do patrimônio espeleológico. No nível federal, o Instituto Chico Mendes de Conservação da Biodiversidade (ICMBio) é o órgão responsável pela gestão das cavidades naturais. Cabe a criação de medidas necessárias ao levantamento de dados, à proteção e ao monitoramento por meio do CANIE e do CECAV (BRASIL 2009).

Posteriormente, a Portaria do MMA $n^{\circ}$ 358/2009, de 30 de setembro, instituiu o Programa Nacional de Conservação do Patrimônio Espeleológico. Fundamentada no valor da biodiversidade, a portaria mantém o dever do Estado na promoção de uma estratégia nacional de conservação e uso sustentável do patrimônio espeleológico brasileiro, preservando-o para as gerações futuras (art. $\left.2^{\circ}, \mathrm{VI}\right)$.

$\mathrm{Na}$ análise dos dispositivos da referida portaria, nomeadamente em seu artigo $4^{\circ}$, verifica-se que ao estabelecer as componentes do Programa Nacional de Conservação do Patrimônio Espeleológico, há semelhanças entre elas e as que suportam uma estratégia de geoconservação. Dentre as componentes, destacam-se a realização de um inventário das cavidades com o diagnóstico das unidades espeleológicas e o posterior plano de manejo para uma utilização sustentável e conservação desse patrimônio. Nesse sentido, HARDT (2015) defende que o inventário é o passo mais importante antes de qualquer ação para preservar e promover o uso consciente dos bens, uma vez que o valor das cavidades naturais não corresponde apenas aos aspectos espeleológicos, envolvendo também aspectos paleontológicos, biológicos e culturais.

Portanto, no que se refere ao patrimônio espeleológico, existem no ordenamento jurídico brasileiro instrumentos legais para a sua proteção direta, fator importante para se implementar uma estratégia de proteção desse patrimônio. Vale destacar que esse dispositivo legal, além de ressaltar como princípio que o valor da biodiversidade é determinado por outros valores, dentre eles o geológico, apresenta pela primeira vez o termo "geodiversidade" no contexto das leis ambientais federais, caracterizando um pequeno avanço no reconhecimento da importância dos elementos da geodiversidade e da necessidade de proteção.

Em nível federal, cabe destacar ainda a criação em 1997 da Comissão Brasileira de Sítios Geológicos e Paleobiológicos - SIGEP, vinculada ao DNPM e à CPRM. Mesmo não relacionada à legislação, foi um dos projetos que impulsionaram os avanços relativos à geoconservação no Brasil, promovendo a inventariação dos sítios geológicos e paleobiológicos. O Serviço Geológico do Brasil - CPRM, também deu sua contribuição ao criar o Projeto Geoparques do Brasil com a finalidade de identificar, levantar e divulgar áreas com potencial para geoparques (SCHOBBENHAUS \& SILVA 2012).

A relevância desses projetos está no fato de servirem de parâmetros para pesquisas e levantamentos acerca dos elementos geológicos relevantes em cada estado. O banco de dados do SIGEP serviu de base para que os geossítios fossem classificados na categoria "Monumento Natural".

\subsection{Leis estaduais}

Os 26 estados brasileiros possuem uma administração autônoma, com um corpo legislativo próprio e políticas públicas relacionadas ao seu território. Assim, cada estado e município, além de respeitar as leis federais, possui a prerrogati- 
va da autonomia na criação de leis para gerir e administrar o desenvolvimento regional e local. Em relação ao meio ambiente, as leis ambientais estaduais são formuladas pelo poder legislativo de cada estado da federação, os quais dispõem de secretarias específicas para administrar as questões relacionadas à política ambiental, respeitando-se a hierarquia dos órgãos federais. $\mathrm{Na}$ análise das leis estaduais, percebem-se alguns avanços na legislação ambiental quanto à defesa dos elementos abióticos. Embora seja uma mudança relativamente pequena, se comparada ao número de estados brasileiros, representa um avanço importante para a inclusão da geoconservação nas políticas ambientais.

No conjunto dos estados brasileiros, São Paulo está na vanguarda pois apresenta dispositivos diretos para a defesa do patrimônio geológico, além do pioneirismo paulista na realização do inventário desse patrimônio (GARCIA et al. 2017).

O estado paulista, com a resolução SMA ${ }^{\circ}$ 76, de 04 de novembro de 2009, criou o Conselho Estadual de Monumentos Geológicos (CoMGeoSP) com a atribuição de reconhecer os monumentos geológicos (SÃO PAULO 2009). Ainda, por meio da Resolução SMA no 46, de 24 de junho de 2015, restaurou o CoMGeo-SP como órgão consultivo para ações de conservação da geodiversidade de São Paulo, definindo em seu artigo $2^{\circ}$ os termos geossítio e geodiversidade, além de prever a realização do Inventário Paulista de Monumentos Geológicos, ao implementar o Inventário do Patrimônio Geológico Paulista. O estado de São Paulo se destaca também pelos Monumentos Geológicos que, atualmente, são sete: Carste e Cavernas do PETAR, Cratera de Colônia, Varvito de Itu, Rocha Mountonné, Pedra do Baú, Morro do Diabo e Geiseritos de Anhembi, criados por meio do decreto estadual em unidades de conservação de proteção integral.

O estado do Paraná também tem importantes iniciativas na proteção do patrimônio geológico: o Parque Estadual de Vila Velha, criado em 1953, foi classificado na categoria de unidade de proteção integral pelo Decreto $\mathrm{n}^{0} 5.767$, de 5 de junho de 2002. Sua área possui relevantes atributos geológicos. Ainda, a Mineropar (Serviço Geológico do Paraná) criou em 2003 o projeto “sítios geológicos e paleontológicos do Paraná, para desenvolver pesquisas, conservação e divulgação do patrimônio geológico da região. No território paranaense, destaca-se também a APA da Escarpa Devoniana, uma área de proteção ambiental de notável beleza cênica e ricos vestígios arqueológicos, criada pelo Decreto $\mathrm{n}^{\circ} 1.231$, de 27 de março de 1992. Recentemente, a comunidade acadêmica e a população do Paraná promoveu protestos contra a aprovação do projeto de Lei $527 / 2016$, que visa alterar os limites territoriais da APA Devoniana, reduzindo sua área em cerca de $70 \%$. Para proteger a Escarpa Devoniana, foi apresentado um pedido de tombamento do patrimônio natural junto à Secretaria de Cultura do Paraná (GUIMARÃES 2017).

No âmbito do estado do Rio de Janeiro, podem ser citadas as iniciativas do Projeto de Tombamento da Armação de Búzios como bem cultural e natural, proposto pelo Instituto Estadual do Patrimônio Cultural - INEPAC (Processo ${ }^{\circ}$ E-18/001.337/2003), o Decreto n ${ }^{\circ} 40.909 / 2007$, que dispõe sobre a Reserva Particular do Patrimônio Natural - RPPN, e o Decreto n41.612/2008 que versa sobre a proteção dos Costões Rochosos. Embora não sejam legislações ambientais voltadas para proteção do patrimônio geológico no estado, são instrumentos importantes para a proteção do valor cultural e natural nessas áreas (MANSUR 2010).

Outro destaque positivo está no pioneirismo do estado do Amazonas ao criar, por meio da Lei $\mathrm{n}^{\mathrm{o}} 3.590 / 2011$, de 18 de fevereiro, a Secretaria de Estado de Mineração, Geodiversidade e Recursos Hídricos - SEMGRH, primeira no Brasil com a finalidade de promover o uso sustentável dos recursos minerais e hídricos. O Rio Grande do Sul, por sua vez, declarou recentemente o Município de Caçapava do Sul "Capital Gaúcha da Geodiversidade" por meio da Lei $n^{\circ} 14.708$, de 15 de julho de 2015.

No geral, as legislações estaduais estão focadas na defesa do meio ambiente relacionada apenas aos aspectos bióticos. Entretanto, mesmo que indiretamente, a proteção é contemplada por algumas leis estaduais (Amapá, Maranhão, Pernambuco, Minas Gerais e Bahia) ao apresentarem dispositivos legais que dispõem sobre as áreas de preservação permanente e espaços ecológicos especialmente protegidos. Nesse âmbito, destacam-se as leis estaduais que versam sobre o Patrimônio Histórico Cultural e o Tombamento como instrumento de proteção ambiental. Os estados do Rio Grande do Sul, Pará e Mato Grosso também apresentam leis para a defesa do referido patrimônio. 


\section{LEGISLAÇÃO APLICADA À GEOCONSERVAÇÃO EM PORTUGAL E ESPANHA}

Em Portugal, a Lei n. ${ }^{\circ}$ 9/1970, de 19 de junho, considerada um marco das políticas de conservação da natureza no país, definiu pela primeira vez a criação de áreas protegidas e estabeleceu a competência do governo para ações de proteção da natureza e promoção do uso racional dos recursos naturais presentes em seu território (BRILHA 2005).

Atualmente, o Decreto-lei $n^{\circ}$ 142/2008, de 24 de julho, é considerado o instrumento mais importante para a geoconservação em Portugal, pois permite proteger o patrimônio geológico. Esse Decreto-lei dispõe sobre o Regime Jurídico da Conservação da Natureza e da Biodiversidade, tendo como um dos seus objetivos promover o reconhecimento, pela sociedade, do valor patrimonial, intergeracional, econômico e social da biodiversidade e do patrimônio geológico. O referido decreto, na definição das áreas protegidas, em seu artigo 14, apresenta claramente a proteção do patrimônio geológico.

Além do Decreto-lei $n^{\circ} 142 / 2008$, de 24 de julho, o patrimônio geológico português conta com a proteção indireta da Lei ${ }^{\circ}$ 58/2007, de 4 de setembro, que dispõe sobre o Programa Nacional da Política de Ordenamento do Território (PNPOT) e a Lei $\mathrm{n}^{\circ} 107 / 2001$, de 8 de setembro, que versa diretamente sobre a proteção e valorização do patrimônio cultural, no qual o paleontológico está inserido.

Muito recentemente, a nova versão da Estratégia Nacional de Conservação da Natureza e Biodiversidade foi publicada pela Resolução do Conselho de Ministros $n^{\circ}$ 55/2018, de 7 de maio. Esse documento é estruturante para a política de conservação da natureza de Portugal a ser implementada até 2030. Destaca-se uma significativa evolução relativa à versão anterior dessa estratégia datada de 2001. A importância da geodiversidade e do patrimônio geológico é inteiramente defendida no documento, permitindo a suposição que, no futuro, a legislação portuguesa de defesa desse patrimônio seja reforçada.

Tal conjunto normativo impulsionou a criação do inventário nacional do patrimônio geológico. Com base no valor científico, configura-se como um importante elemento para a implementação da estratégia de geoconservação no país. Os trabalhos iniciaram-se em 2003, com a identificação de 27 ca- tegorias geológicas temáticas e 326 geossítios com valor científico (BRILHA 2010).

Cabe destacar que as regiões autônomas de Portugal (Açores e Madeira) possuem legislação própria relativas à conservação da natureza, embora enquadradas pela legislação nacional. Na região autônoma dos Açores, a proteção do patrimônio geológico está integrada à legislação regional de conservação da natureza (DLR n ${ }^{\circ}$ 21/1993/A, de 23 de dezembro e DLR n ${ }^{\circ} 15 / 2007$, de 25 de junho). Já na região autônoma da Madeira, a organização das leis relativas à conservação da natureza é diferenciada. O Decreto Regional n ${ }^{\circ}$ 14/1982/M, de 10 de novembro, foi o primeiro instrumento de conservação ao criar o Parque Natural da Madeira, mas sem referências ao patrimônio geológico. Porém, o Decreto Legislativo Regional $\mathrm{n}^{\circ}$ 24/2004, de 20 de agosto, apresenta-se como o primeiro dispositivo legal específico para a proteção do patrimônio geológico em Portugal. Em seu artigo $2^{\circ}$, destaca os objetivos de preservação e conservação desse patrimônio no arquipélago da Madeira.

Para dar continuidade às medidas de geoconservação na região, a Resolução $n^{\circ} 883 / 2015$, de 7 de outubro, dispõe sobre as estratégias de geoconservação para a proteção do patrimônio geológico no arquipélago.

Assim, com base nessa breve análise dos dispositivos legais em Portugal, percebem-se avanços significativos no enquadramento e classificação do patrimônio geológico na legislação portuguesa de conservação da natureza.

A Espanha possui um histórico relevante no estudo e enquadramento legal dos elementos geológicos do seu território, uma vez que a primeira iniciativa no contexto da conservação da natureza foi a aprovação da Lei de Parques Nacionais, em 8 de dezembro de 1916.

Atualmente, a Espanha conta com três importantes leis que versam diretamente sobre a proteção do patrimônio geológico: Lei $n^{0} 5 / 2007$, de 3 de abril; Lei $n^{\circ} 42 / 2007$, de 13 de dezembro; e Lei $n^{\circ} 45 / 2007$, de 13 de dezembro. A Lei no 42/2007, 13 de dezembro é considerada a mais adequada para a geoconservação porque está diretamente voltada para a regulamentação da proteção do patrimônio geológico. De acordo com MONDÉJAR (2013), a referida lei, ao definir patrimônio natural, expressa diretamente ou indiretamente a conservação, gestão e uso da geodiversidade e do patrimônio geológico. O pesquisador CARCAVILLA (2014) confirma que não há outro instrumento legal mais favorável para a geoconservação na Espanha. 
Em relação às comunidades autônomas, das 17 existentes, 16 contam com dispositivos legais que protegem direta ou indiretamente a geoconservação. Apenas Madrid não possui lei autônoma de conservação e aplica a lei nacional.

Quanto às estratégias da geoconservação, cada comunidade implementou a realização de inventários. Além de adotarem a Lei $n^{\circ} 42 / 2007$, de 13 de dezembro, com adaptações, as comunidades possuem leis próprias para a proteção dos patrimônios natural e paleontológico. Baseando-se na Lei Nacional $\mathrm{n}^{\circ} 16 / 85$, de 25 de junho, cada comunidade autônoma possui uma legislação específica para o patrimônio histórico cultural que contempla a proteção do patrimônio paleontológico (DÍAZ MARTINEZ et al. 2014).

A Lei $\mathrm{n}^{\circ}$ 42/2007, de 13 de dezembro, bem como o Decreto-lei no 142/2008, de 24 de julho, da Espanha e de Portugal respectivamente, são marcos legais relevantes para a proteção do patrimônio geológico dos países ibéricos. $\mathrm{Na}$ análise das duas legislações, percebem-se as singularidades e semelhanças no tratamento do tema. A Lei $n^{\circ} 42 / 2007$ espanhola se destaca pelo enfoque na geodiversidade como um de seus princípios, além de defender, em seu artigo 12, alguns critérios e ações para a sua conservação na mesma igualdade que a biodiversidade. Já o Decreto-lei $n^{\circ} 142 / 2008$ define e utiliza "patrimônio geológico" e "geossítios". No entanto, não expressa diretamente a geodiversidade que está incluída indiretamente na proteção do patrimônio geológico no âmbito da definição das áreas protegidas (art. 14, $\mathrm{n}^{\circ} 3$, alínea d).

Com base na análise da bibliografia, constata-se que a gestão do patrimônio geológico nesses países é semelhante, uma vez que ambos desenvolveram uma estratégia de geoconservação elencando etapas que envolvem o governo, a comunidade científica e a sociedade. Destaca-se também o papel da sociedade civil na formulação da legislação sobre a conservação da natureza, tanto na Espanha quanto em Portugal. No momento da audiência pública durante o processo de redação das leis, foram incorporadas inúmeras sugestões das comunidades geológicas de ambos os países (Instituto Geológico e Mineiro e a Sociedade Geológica na Espanha e o Grupo Nacional da ProGEO, em Portugal).

Conforme apontado por FERREIRA (2016), as iniciativas e avanços dos dois países europeus na geoconservação são exemplos a serem seguidos pelo Brasil, respeitando-se as especificidades do território nacional, dificuldades e as questões políticas que envolvem as ações de conservação ambiental.

\section{CONCLUSÃO}

A comunidade geocientífica brasileira considera que o Brasil não possui instrumentos legais para a proteção do patrimônio geológico, apontando apenas o Decreto-lei no 25/1937 (Proteção do Patrimônio Histórico e seu Tombamento) e a Lei $\mathrm{n}^{\circ}$ 9.985/2000 (SNUC) como o arcabouço jurídico mais adequado. No entanto, constatou-se que o patrimônio geológico brasileiro possui outras leis para a proteção direta nas modalidades de patrimônios paleontológico e espeleológico, existindo para o último um Programa Nacional de Proteção com um inventário em andamento. Com base na análise da legislação ambiental brasileira, pode-se afirmar que as cavidades naturais subterrâneas existentes no território nacional se encontram bem representadas juridicamente.

O patrimônio paleontológico está integrado na lei para a proteção do patrimônio histórico cultural desde a publicação do Decreto-lei no 25/1937, de 30 de novembro, sendo protegido por meio do ato administrativo do tombamento. Posteriormente, o Decreto-lei no 4.146/1942, de 4 de março, atribuiu ao DNPM a competência para fiscalizar e autorizar ações relativas a esse patrimônio; mais tarde, a Constituição de 1988 (art. 216, V) o classifica como bem cultural. No entanto, tal classificação tem sido apontada pela comunidade geocientífica como uma fragilidade da Administração Pública para a proteção desse tipo de patrimônio geológico, uma vez que as instituições responsáveis pela gestão do patrimônio cultural não possuem um corpo técnico adequado para cuidar do registro fóssil.

O Brasil, apesar de apresentar avanços significativos em relação à legislação para proteção do patrimônio geológico ainda deve melhorar a implementação de uma estratégia de geoconservação.

No caso dos países ibéricos, a assertividade nas iniciativas tomadas pelas instituições acadêmicas (ProGEO-Portugal, Sociedade Geológica da Espanha e Instituto Geológico e Mineiro da Espanha) no momento das audiências públicas, têm impactado positivamente a legislação ambiental de ambos os países. Oportunamente, tais iniciativas poderiam ser também praticadas no Brasil.

Desse modo, apesar da existência de leis brasileiras com vistas à proteção do patrimônio geológico (em especial nas suas componentes paleontológicas e espeleológicas), o questionamento que surge é saber como o Estado efetivamente as aplica e fiscaliza, a fim de garantir a compatibiliza- 
ção entre o desenvolvimento econômico-social, a proteção ambiental e o equilíbrio ecológico.

\section{AGRADECIMENTOS}

Aos relatores da Revista do Instituto Geológico pelas sugestões apresentadas.

\section{REFERÊNCIAS}

ABAIDE, J.P. 2009. Fósseis: riqueza do subsolo ou bem ambiental? Juruá, Curitiba, $2^{\mathrm{a}}$ ed., 348 p.

BRILHA, J. 2005. Património geológico e geoconservação: a conservação da natureza na sua vertente geológica. Palimage Editores, Braga, $190 \mathrm{p}$.

BRILHA, J. 2010. Enquadramento legal de suporte à proteção do património geológico em Portugal. In: J.M. Neiva (Ed.) Ciências Geológicas: ensino, investigação e sua história - volume II. Porto, Associação Portuguesa de Geólogos, capítulo IV, p. 443-450.

BRASIL. 1977. Decreto Lei ${ }^{\circ} 80.978$, de 12 de dezembro de 1977: Promulga a Convenção relativa à Proteção do Patrimônio Mundial, Cultural e Natural. Brasília: Presidência da República. Disponível em http:// portal.iphan.gov.br/uploads/legislacao/ DecretoLei_n_80.978_de_12_de dezembro_de_1977.pdf. Acessado em 10 set. 2015.

BRASIL. 1981. Lei $\mathrm{n}^{\circ} 6.938$, de 31 de agosto de 1981: Dispõe sobre a Política Nacional do Meio Ambiente. Brasília: Presidência da República. Disponível em http://www. planalto.gov.br/ccivil_03/Leis/L6938.htm. Acessado em 13 set. 2015.

BRASIL. 1988. Constituição Federal da República Federativa do Brasil, de 5 de outubro de 1988. Brasília: Senado Federal. Presidência da República. Disponível em http://www. planalto.gov.br/ccivil_03/constituicao/ constituicao.htm. Acessado em 15 set. 2015.

BRASIL. 2000. Lei $\mathrm{n}^{\circ}$ 9.985/2000, de 18 de julho de 2000: cria o Sistema Nacional das Unidades de Conservação - SNUC. Brasília: Presidência da República. Disponível em http://www.planalto.gov.br/ccivil_03/Leis/ L9985.htm. Acessado em 2 set. 2015.
BRASIL. 2009. Portaria ICMBio $n^{\circ} 078$ de 03 de setembro de 2009: dispõe sobre a criação do Centro Nacional de Pesquisa e Conservação de Cavernas CECAV. Brasília: ICMBio. Disponível em http://www.icmbio.gov. $\mathrm{br} /$ cecav/images/download/Portaria $\% 20$ N\%C2\%BA78_030909_cria\%20CECAV. pdf. Acessado em 4 mar. 2016.

CARCAVILLA, L. 2012. Geoconservación: un recorridopor lugares geológicos excepcionales para entender como y por qué debemos protegerlos. Catarata, Madrid, $128 \mathrm{p}$.

CARCAVILLA, L. 2014. Guía práctica para entender el patrimônio geológico. Enseñanza de Las Ciências de La Tierra, 22(1): 5-18.

DÍAZ-MARTÍNEZ, E.; SALAZAR, A.E.; GARCÍA-CORTÉS, Á. 2014. El patrimonio geológico en España. Enseñanza de Las Ciencias de La Tierra, 22(1): 25-37.

FERREIRA, M.W.S. 2016. Enquadramento legal e institucional para a promoção da geoconservação no Brasil e propostas de desenvolvimento. Departamento de Ciências da Terra, Universidade do Minho, Braga, Portugal, Dissertação de Mestrado, 140 p.

GARCIA, M.G.M.; BRILHA, J.; LIMA, F.F.; VARGAS, J.C.; PÉREZ-AGUILAR A.; ALVES, A.; CAMPANHA, G.A.C.; DULEBA, W.; FALEIROS, F.M.; JANASI, V.A.; MARTINS, L. RAPOSO, M.I.B.; RICARDI-BRANCO, F.; ROSS, J.L.S.; SALLUM FILHO, W.; SOUZA, C.R.G.; BERNARDES-DE-OLIVEIRA, M.E.C.; NEVES, B.B.B.; CAMPOS NETO, M.C.; CHRISTOFOLETTI, S.R.; HENRIQUEPINTO, R.; LOBO, H.A.S.; MACHADO, R.; PASSARELI, C.R.; PERINOTTO, J.A.J.; RIBEIRO, R.R.; SHIMADA, H. 2017. The Inventory of Geological Heritage of the State of São Paulo, Brazil: Methodological Basis, Results and Perspectives. Geoheritage, 10(2): 239-258.

GRAY, M. 2004. Geodiversity: valuing and conserving abiotic nature. John Wiley \& Sons, London, $434 \mathrm{p}$.

GUIMARÃES, G.B. 2017. APA da Escarpa Devoniana pode perder $70 \%$ de sua área. Disponível em https://www.oeco.org. 
$\mathrm{br} / \mathrm{colunas} /$ colunistas-convidados/areaprotegida-no-parana-pode-ter-sua-dimensaoreduzida-para-menos-de-um-terco/. Acessado em 19 jul. 2018.

HARDT, R. 2015. Breve inventário do patrimônio espeleológico. In: Ú.A. RUCHKYS, L.E.P. TRAVASSOS, M.A. RASTEIRO, L.E. FARIA (eds.) Patrimônio espeleológico em rochas ferruginosas: propostas para sua conservação no Quadrilátero Ferrífero, Minas Gerais. Campinas, Sociedade Brasileira de Espeleologia, $345 \mathrm{p}$.

IBGE. 2015. Áreas de Municípios. Disponível em https://www.ibge.gov.br/geocienciasnovoportal/organizacao-do-territorio/ estrutura-territorial/15761-areas-dosmunicipios.html? $=\& \mathrm{t}=\mathrm{O}-\mathrm{que}-\mathrm{e}$. Acessado em 15 jul. 2015.

LITTLE, P.E. 2003. Políticas ambientais no Brasil: análises, instrumentos e experiências. Editora Peirópolis, São Paulo, $2^{\mathrm{a}}$ ed., 220 p.

MANSUR, K.L. 2010. Ordenamento Territorial e Geoconservação: análise das normas legais aplicáveis no Brasil e um caso de estudo no Estado do Rio de Janeiro. Geociências, 29(2): 237-249.

MONDÉJAR, F.G. 2013. La diversidad Geológica y su Patrimonio, el legado de nuestro planeta a la humanidad. Propuestas para la legislación de su uso y gestión basadas en las normativas internacionales y españolas sobre Geoconservación. Depósito Legal, p. 130-152.

PEREIRA, R.G.F.A. 2010. Geoconservação e desenvolvimento sustentável na Chapada Diamantina (Bahia-Brasil). Universidade do Minho, 295 p.

RONCAGLIO, C.; JANKE, N. 2009. Desenvolvimento sustentável. IESDE Brasil. Curitiba, 116 p.

RUCHKYS, Ú. 2015. Patrimônio espeleológico em rochas ferruginosas: propostas para a conservação no quadrilátero ferrífero, Minas Gerais. Sociedade Brasileira de Espeleologia, Campinas, $1^{\mathrm{a}}$ ed., $345 \mathrm{p}$.

SÃO PAULO. 2009. Resolução da Secretaria de Estado do Meio Ambiente n ${ }^{\circ}$ 079, de 04 de novembro de 2009. Dispõe sobre a criação do Conselho Estadual de Monumentos Geológicos no Estado de São Paulo. Disponível em http://www2.ambiente.sp.gov. $\mathrm{br} /$ legislacao/resolucoes-sma/resolucao-sma79-2009-2/. Acessado em 6 ago. 2018.

SCHOBBENHAUS, C.; SILVA, C.R. 2012. Geoparques do Brasil: propostas. CPRM, Rio de Janeiro, v. 1, 748 p.

WAINER,A.H. 1999. Legislação ambiental brasileira: subsídio para a história do Direito Ambiental. Forense, Rio de Janeiro, $2^{\mathrm{a}}$ ed., $112 \mathrm{p}$.

\section{Endereço dos autores:}

Magda Wolemberg da Silva Ferreira e José Bernardo Rodrigues Brilha - Instituto de Ciências da Terra, Polo da Universidade do Minho, Campus de Gualtar, CEP 4710-057, Braga, Portugal. E-mails: magdaferreira81@gmail.com,jbrilha@dct.uminho.pt

Adriana Ponce Coelho Cerântola - Faculdades Oswaldo Cruz, Rua Brigadeiro Galvão, 540, Barra Funda, CEP 01151-000, São Paulo, SP, Brasil.E-mail: adrianaponce.adv@gmail.com

Artigo submetido em 30 de maio de 2018, aceito em 20 de agosto de 2018. 